\title{
Interaction of Arg194Trp and Arg399GIn genotypes with the risk of radiation on cancer patients
}

\author{
HARRY NUGROHO EKO SURNIYANTORO ${ }^{1, \bullet}$, NASTITI RAHAJENG ${ }^{1}$, YANTI LUSIYANTI ${ }^{1}$, \\ TUR RAHARDJO ${ }^{1}$, DYAH ERAWATI ${ }^{2}$, LINA CHORIDAH ${ }^{3}$, WIGATI DHAMIYATI ${ }^{3}$, \\ SRI RETNA DWIDANARTI ${ }^{3}$ \\ ${ }^{1}$ Center for Technology of Radiation Metrology and Safety, National Nuclear Energy Agency of Indonesia. Jl. Lebak Bulus Raya No. 49, Jakarta 12070, \\ Indonesia. Tel.: +62-21-7513906, ^email: harry_nes@batan.go.id \\ ${ }^{2}$ Department of Radiotherapy, dr. Soetomo General Academic Hospital. Surabaya 60286, East Java, Indonesia \\ ${ }^{3}$ Department of Radiology, dr. Sardjito General Hospital, Sleman 55281, Yogyakarta, Indonesia
}

Manuscript received: 26 April 2019. Revision accepted: 12 July 2019.

\begin{abstract}
Surniyantoro HNE, Rahajeng N, Lusiyanti Y, Rahardjo T, Erawati D, Choridah L, Dhamiyati W, Dwidanarti SR. 2019. Interaction of Arg194Trp and Arg399Gln genotypes with the risk of radiation on cancer patients. Biodiversitas 20: 2128-2133. Two of the common single-nucleotide polymorphisms are X-ray repair cross-complementary group 1 on exon 6 (Arg194Trp) and exon 10 (Arg399Gln). The purpose of this study was to determine the interactions between Arg194Trp and Arg399Gln genotypes combination with the risk of radiation on cancer patients in Indonesia, linked to micronuclei frequency as a biomarker of DNA damage. This study consisted of 19 patients with various cancer as the case group and 37 non-cancer participants as the control group. The determination of Arg 149Trp and Arg399Gln alleles were performed using Polymerase Chain Reaction-Restriction Fragment Length Polymorphism. Micronuclei assay was performed using Cytokinesis-block micronuclei cytome assay. The results of our study showed that micronuclei frequency was very significantly higher in the cancer patients compared to controls $(111.16 \pm 76.24$ versus $16.89 \pm 9.72, \mathrm{p}<0.0001)$. Patients with heterozygous mutant genotypes CT had a lower frequency of micronuclei than patients with normal CC genotypes (105.6 \pm 80.97 versus $117.33 \pm 74.97)$. Likewise, patients with mutant genotype AA had a lower frequency of micronuclei than patients with normal GG genotype (64 versus $129.71 \pm 90.68$ ). The genetic polymorphisms of Arg194Trp and Arg399Gln demonstrated an association with the level of DNA damage on cancer patients.
\end{abstract}

Keywords: 194Trp, 399Gln, micronuclei, radiation, cancer patients

\section{INTRODUCTION}

Diseases such as obesity, type 2 diabetes, heart disease, and especially cancer, caused by many factors, i.e. lifestyle, environmental factors, and, of course, genetic factors. Genetic factors are not only caused by a single-gene but can consist of several genes. Diseases caused by many contributing factors are called multifactorial disorders (Surniyantoro et al. 2018a). A previous study by Demant (2005) showed that the same level of deoxyribonucleic acid (DNA) damage or mutations in oncogenes and tumor suppressors in different hosts resulted in very different cancer developments because of many genes of polymorphic tumor susceptibility. Even susceptibility to cancer in humans is strongly influenced by several polymorphic genes with relatively weak effects.

Two of the common single-nucleotide polymorphisms (SNPs) are X-ray repair cross-complementary group 1 (XRCC1) on exon 6 (Arg194Trp) and exon 10 (Arg399Gln). XRCC1 is a $69 \mathrm{kDa}$ protein, located at chromosome $19 q 13.2-13.3$, that interacts with DNA and polymerase $\beta$ dubbed through the N-terminal domain, Ligase 3 through the C-terminal BRCT2 domain, polynucleotide kinase phosphatase (PNKP), and several treatment processes, depending on type and location of the damage (Wells and El-Khamisy 2015; Caldecott et al.
2008). XRCC1 is an important protein needed for maintaining genome stability through DNA repair pathways. The main function of XRCC1 is associated with its role in the path of single-strand breaks (SSBs) damage and base excision repair (BER) pathways through the enzymatic stage (Campalans et al. 2015; Norjmaa et al. 2016). XRCC1 gene polymorphism that occurs in DNA repair genes resulting in decreased DNA repair ability, increased mutation rate and cancer risk such as breast, prostate cancer, cervical cancer, and lung cancer (Moullan et al. 2003; Rybicki et al. 2004; Ochiai 2015; Yuan et al. 2015; Meng et al. 2017).

One of the DNA damage predictors is micronuclei, which is formed from fragments of chromosomes left in anaphase during the process of cell division (Fenech 2007). A previous study by Surniyantoro et al. (2018b) stated that heterozygous allele 194Trp of XRCC1 exon 6 polymorphism showed a significantly higher micronuclei frequency in human exposure to ionizing radiation than controls. In human DNA, there is a significant correlation between equivalent dose and micronuclei frequency among radiation-exposed workers, increasing the micronuclei frequency by 16.3 per $1 \mathrm{mGy}$ of equivalent dose (Surniyantoro et al. 2018c). In determining two-way gene interactions, it is necessary to study the effect of the $194 \mathrm{Trp}$ and $399 \mathrm{Gln}$ alleles combination on the level of 
DNA damage indicated by micronuclei frequency values. The purpose of this study was to determine the interactions between Arg194Trp and Arg399Gln genotypes combination with the risk of radiation on cancer patients in Indonesia, linked to micronuclei frequency as a biomarker of DNA damage.

\section{MATERIALS AND METHODS}

\section{Study population}

This study was a case-control study. Subjects consisted of 18 patients with various cancers in the Radiology and Radiotherapy installation at dr. Soetomo, Surabaya, and dr. Sarjito, Yogyakarta General Hospitals, Indonesia as a case group and 37 non-cancer participants as a control group who had never been occupationally exposed to ionizing radiation. Questionnaires were given to the subjects to find out complete information about gender, age, and history of disease ever suffered. The cancer types of patients are shown in Table 1. Each subject was briefed about the protocol, with specific information about the cytogenetic test, the aim of the study and signed informed consent. Blood samples $(5 \mathrm{~mL})$ was obtained from each subject (patients and controls) and taken to the Molecular Biology laboratory, Center for Technology of Safety and Radiation Metrology, National Nuclear Energy Agency of Indonesia, Jakarta for further analysis.

\section{Procedures}

DNA isolation

DNA was isolated from blood lymphocytes using the QIAamp DNA Kit (Qiagen) according to the manufacturer's instructions. The obtained DNA was stored at $-20^{\circ} \mathrm{C}$.

\section{Determination of Arg149Trp and Arg399Gln}

Determination of Arg 149Trp and Arg399Gln genotypes were performed using Polymerase Chain ReactionRestriction Fragment Length Polymorphism (PCR-RFLP), as described previously by Ryu et al. (2011) with the forward primer was 5'-GCCCCGTCCCAGGTA-3' and the reverse primer was 5'-AGCCCCAAGACCCTTTCACT-3' for Arg149Trp, and by Andreassi et al. (2009) with the forward primer was 5'- AGTAGTCTGCTGGCTCTGG-3' and the reverse primer was 5' TCTCCCTTGGTCTCCAACCT-3' for Arg399Gln. The PCR reactions were carried out with a denaturation of $95^{\circ} \mathrm{C}$ for 3 minutes, followed by 35 cycles of 15 seconds at $95^{\circ} \mathrm{C}$ (denaturation), 15 seconds at $60^{\circ} \mathrm{C}$ (annealing) and 15 seconds at $72^{\circ} \mathrm{C}$ (extension) and finally 1 minute at $72^{\circ} \mathrm{C}$ (final extension). Following amplification, PCR products of 149Trp and 399Gln were digested using $5 \mathrm{U}$ of $\mathrm{MspI}$ restriction enzyme (BioLabs, Inc.) for 2 hours at $37^{\circ} \mathrm{C}$, and electrophoresed on a $3 \%$ agarose gel. The mutant allele 194Trp was determined by the presence of 313 and 174 bp bands, while the mutant allele $399 \mathrm{Gln}$ was determined by the presence of the uncut 402 bp band.

\section{Micronuclei assay}

The cytokinesis-block micronuclei (CBMN) cytome assay was performed as described by Fenech (2007) with modification (Lusiyanti et al. 2016). Lymphocyte cultures were incubated for 48 hours at $37^{\circ} \mathrm{C}$ and then a $3 \mathrm{~g} / \mathrm{mL}$ of cytochalasin-B (Sigma-Aldrich, St. Louis) was added to the cultures after 44 hours of incubation in order to block the cytokinesis process. The cultures were finished at 72 hours, treated with a hypotonic solution for 4 minutes and fixed with two changes of methanol: acetic acid (3: 1, v/v). The fixed cells were spread onto a glass slide and stained for 10 minutes with a $4 \%$ Giemsa solution. Microscopic analysis was performed under a light microscope with a 40x10 magnification and CBMN assay parameters of micronuclei, verified under 1000x magnification. A score was obtained for slides from each participant. The frequency of binucleated cells containing one or more micronuclei was scored in 1000 cells per subject, in order to determine cytotoxicity in accordance with published CBMN-Cytome scoring-criteria refers to IAEA manual (Fenech 2007).

\section{Data analysis}

The statistical analysis of the data was conducted with SPSS v.16 for Windows. All of the data were expressed as mean \pm SD. Independent sample T-test was used to test micronuclei frequencies difference between case and controls and to test a significant relationship between micronuclei and various genotypes or alleles. The genotype and allele frequencies were showed on frequencies distribution table and were checked for consistency with Hardy-Weinberg equilibrium and compared between the radiation workers and controls group by $\chi 2$ tests. The level of significance was set at $\mathrm{P}<0.05$.

\section{RESULTS AND DISCUSSION}

\section{Frequency of micronuclei}

There are 19 patients with ten different types of cancers: Parotid ca., Breast ca., Cervical ca., Thyroid ca., Nasopharyngeal ca., Rectal ca., Sinonasal ca., Basal cell ca., Tongue ca., and Humerus ca. The number of patients for each type of cancer has shown in Table 1. All of the patients obtained from dr. Soetomo General Hospital, Surabaya and dr. Sardjito General Hospital, Yogyakarta. Micronucleus $(\mathrm{MN})$ assay results were reported as a total number of micronucleus per 1000 binucleated (BN) cells in genotypes or alleles stratification and presented in Table 2. $\mathrm{MN}$ frequencies were significantly higher in the case group compared to the controls $(111.16 \pm 76.24$ versus $16.89 \pm$ 9.72, $\mathrm{p}<0.0001)$. The case group did not have members with TT genotype, so the MN frequencies in the case group of TT genotype was not compared with the MN frequency in the control group.

\section{Genotype analysis of Arg194Trp and Arg399Gln}

In this study, the single nucleotide polymorphisms (SNPs) of Arg194Trp and Arg399Gln were investigated. The genotype analysis for patients was performed using the PCR-RFLP method. The genotyping results are shown in 
Figure 1. Based on Figure 1, CC genotype (wild-type) was showed with $292+174$ bp fragment length, CT genotype (mutant heterozygous) with $313+292+174 \mathrm{bp}$, and TT genotype (mutant homozygous) with $313+174 \mathrm{bp}$, while GG genotype (wild-type) was shown with $269+133$ bp fragment length, GA genotype with $402+269+133 \mathrm{bp}$, and AA genotype (mutant homozygous) with 402 bp.

The genotypes and alleles distribution were consistent with the Hardy-Weinberg equilibrium for all the SNPs studied, both in case and controls group, as shown in Table 3. The frequencies of Arg 194Trp genotypes for case group were CC $(47.37 \%)$ and CT $(52.63 \%)$ with a frequency of C and $\mathrm{T}$ allele was 0.74 and 0.26 , respectively. The frequencies of Arg194Trp genotypes for controls were CC $(51.35 \%)$, CT $(43.24 \%)$ and TT $(5.41 \%)$, with a frequency of $\mathrm{C}$ and $\mathrm{T}$ allele was 0.73 and 0.27 , respectively. The results of the $\chi 2$-test showed no significant difference in the genotypes and alleles between case and controls group $(\mathrm{P}=0.62$ and 0.89). The frequencies of Arg399Gln genotypes for case group were GG $(36.84 \%)$, GA $(57.9 \%)$ and AA $(5.26 \%)$ with a frequency of $\mathrm{G}$ and $\mathrm{A}$ allele was
0.66 and 0.34, respectively. The frequencies of Arg399Gln genotypes for controls were GG (35.14\%), GA (54.05\%) and AA (10.81\%), with a frequency of $\mathrm{G}$ and $\mathrm{A}$ allele was 0.62 and 0.38 , respectively. The results of the $\chi 2$-test showed no significant difference in the genotypes and alleles between case and controls group $(\mathrm{P}=0.79$ and 0.71$)$.

Table 1. Types of cancer in the study population

\begin{tabular}{lccc} 
& Patients & Controls & Total \\
\hline Sample size (N) & 19 & 37 & 56 \\
Parotid ca. & 2 & & \\
Breast ca. & 4 & & \\
Cervical ca. & 4 & & \\
Thyroid ca. & 1 & & \\
Nasopharyngeal ca. & 1 & & \\
Rectal ca. & 1 & & \\
Sinonasal ca. & 1 & & \\
Basal cell ca. & 1 & & \\
Tongue ca. & 3 & \\
Humerus ca. & 1 & \\
\hline
\end{tabular}

Table 2. Micronuclei frequencies in the study population

\begin{tabular}{|c|c|c|c|c|c|}
\hline \multirow{2}{*}{ Genotypes } & \multicolumn{2}{|c|}{ Patients } & \multicolumn{2}{|c|}{ Controls } & \multirow[b]{2}{*}{$p$} \\
\hline & Subjects & $\mathrm{MN} \pm \mathrm{SD}$ & Subjects & $\mathrm{MN} \pm \mathrm{SD}$ & \\
\hline All & 19 & $111.16 \pm 76.24^{*}$ & 37 & $16.89 \pm 9.72$ & $<0.0001$ \\
\hline \multicolumn{6}{|l|}{ Arg 194Trp } \\
\hline $\mathrm{CC}$ & 9 & $117.33 \pm 74.97 *$ & 19 & $16.89 \pm 7.63$ & 0.004 \\
\hline $\mathrm{CT}$ & 10 & $105.6 \pm 80.97 *$ & 16 & $16.56 \pm 10.8$ & 0.007 \\
\hline $\mathrm{TT}$ & - & - & 2 & $19.50 \pm 26.16$ & - \\
\hline \multicolumn{6}{|l|}{ Arg399Gln } \\
\hline GG & 7 & $129.71 \pm 90.68^{*}$ & 13 & $16.77 \pm 9.84$ & 0.016 \\
\hline GA & 11 & $103.63 \pm 70.73 *$ & 20 & $18.00 \pm 9.85$ & 0.002 \\
\hline $\mathrm{AA}$ & 1 & $64 \pm 0.00^{*}$ & 4 & $11.75 \pm 8.13$ & 0.003 \\
\hline
\end{tabular}

Note: * The mean difference is significant at the 0.05 level. An independent sample T-test was used for comparison of MN frequencies between case and controls

Table 3. Genotype and allele frequencies of Arg194Trp and Arg399Gln in the study population

\begin{tabular}{|c|c|c|c|c|c|}
\hline & $\begin{array}{c}\mathbf{N} \\
(56)\end{array}$ & $\%$ & $\begin{array}{c}\text { Patients } \\
(\mathrm{n}=19)(\%)\end{array}$ & $\begin{array}{l}\text { Controls } \\
(\mathrm{n}=37)(\%)\end{array}$ & p value \\
\hline \multicolumn{6}{|l|}{$\overline{\text { Arg194Trp }}$} \\
\hline $\mathrm{CC}$ & 28 & 50 & $9(47.37)$ & $19(51.35)$ & 0.62 \\
\hline CT & 26 & 46.43 & $10(52.63)$ & $16(43.24)$ & \\
\hline TT & 2 & 3.57 & - & $2(5.41)$ & \\
\hline \multicolumn{6}{|l|}{ Allele } \\
\hline$p C$ & & & 0.74 & 0.73 & 0.89 \\
\hline$q T$ & & & 0.26 & 0.27 & \\
\hline \multicolumn{6}{|l|}{ Arg399Gln } \\
\hline GG & 20 & 35.71 & $7(36.84)$ & $13(35.14)$ & 0.79 \\
\hline GA & 31 & 55.36 & $11(57.9)$ & $20(54.05)$ & \\
\hline AA & 5 & 8.93 & $1(5.26)$ & $4(10.81)$ & \\
\hline \multicolumn{6}{|l|}{ Allele } \\
\hline$p G$ & & & 0.66 & 0.62 & 0.71 \\
\hline$q A$ & & & 0.34 & 0.38 & \\
\hline
\end{tabular}




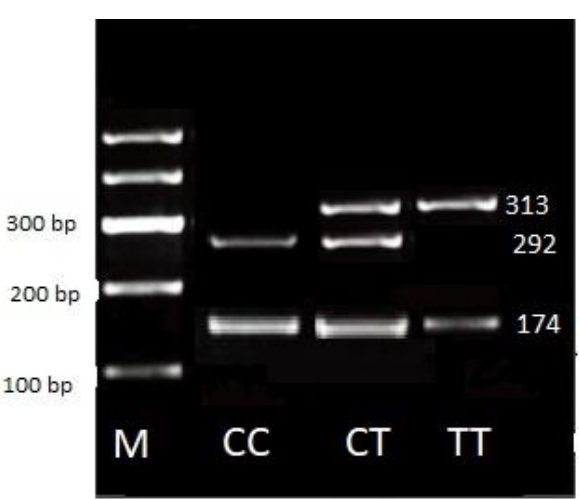

$\mathbf{A}$

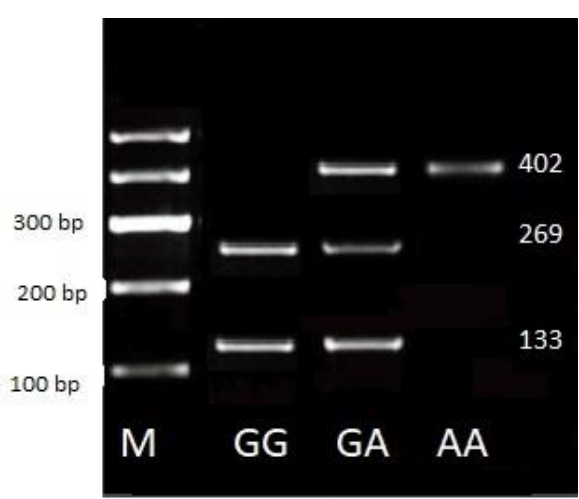

B

Figure 1. Results of genotyping for: (A). Arg194Trp polymorphism of XRCC1 exon 6. CC (wild-type), CT (mutant heterozygous), TT (mutant homozygous) and (B) Arg399Gln polymorphism of XRCC1 exon 10 gene on 3\% electrophorese gel. GG (wild-type), GA (mutant heterozygous), AA (mutant homozygous), M (DNA ladder $100 \mathrm{bp}$ )

\section{Discussion}

The strength and novelty of this study is the investigation of Arg194Trp and Arg399Gln genotypes with the risk of radiation on cancer patients, linked to the micronuclei as a biological marker of the DNA damage. To our best knowledge, this study has not been done in Indonesia. The use of micronuclei as one of the cytogenetic damage biomarkers has some advantages, which can be measured in biopsy and does not reveal genetic instability that is the same as conventional genome testing. The differences between this study and the previous study are the application of micronuclei as a biomarker of DNA damage and the results suggested that a wild-type genotypes have a greater risk of DNA damage than mutant genotypes (Gong et al. 2015). It can open a new perspective on the classification of cancer with genetic instability (Jdey et al. 2017).

The results of our study showed that MN frequency was significantly higher in the cancer patients compared to controls $(111.16 \pm 76.24$ versus $16.89 \pm 9.72, \mathrm{p}<0.0001)$. This is in accordance with a study by Fenech et al. (1999), which stated that a high $\mathrm{MN}$ level in cancer patients could be a consequence of the disease or reflect an individual's susceptibility to events causing genomic instability. A possible explanation was associated with oxidative stress level. Greer and Whitcomb (2009) stated that oxidative stress plays an important role in numerous pathologies, including cancer cells development. A previous study found that the background and $\mathrm{H}_{2} \mathrm{O}_{2}$ induced $\mathrm{MN}$ frequencies were parallel by measured the $\mathrm{MN}$ frequency in peripheral lymphocytes treated in vitro with $\mathrm{H}_{2} \mathrm{O}_{2}$. It means that those with a higher level of background $\mathrm{MN}$ also had a higher level of $\mathrm{H}_{2} \mathrm{O}_{2}$-induced $\mathrm{MN}$, suggesting that the individual did indeed have an increased susceptibility to oxidative stress. These observations suggest an association between elevated level of background $\mathrm{MN}$ and increased risk of cancer, especially in pancreatic cancer (Chang et al. 2010). Several previous studies suggested that an elevated level of $\mathrm{MN}$ in peripheral lymphocytes was associated with an increased risk of pancreatic cancer (Chang et al. 2010), patients with breast cancer families (Rothfuss et al. 2000) cervical carcinoma (Widel et al. 1999), and oral squamous cell carcinoma (Jadhav et al. 2011).

Cancer is caused by various entities comprising genetics, lifestyle, functionality, reproductive system, environmental factors and linked with the swinging balance between DNA damage build up and DNA repair failure (Jain et al. 2017). One of the reasonable mechanism is the role of abnormal DNA repair and compensation between genotypically different cancer cells (Khanna 2015; O'Connor 2015). The most of DNA repairs system used in human to remove the endogenous DNA damages produced daily in each human cell is Base excision repair (BER). It is required for normal mammalian development and defects have been associated with cancer (Wallace et al. 2012). Many studies in DNA repair gene polymorphisms have shown the significant effect of many of these polymorphisms in the ability to repair DNA damage, thus influencing individual susceptibility to carcinogenesis (Mandal et al. 2010). A previous study on 399Gln XRCC1 allele apparently increased the risk of colon cancer (Jelonek et al. 2010). It means patients with 194Trp and 399Gln alleles should have a higher frequency of chromosomal change. Interestingly, individuals with mutant genotypes do not always have negative effects. In our study, patients with heterozygous mutant genotypes CT had a lower frequency of micronucleus than patients with normal CC genotypes $(105.6 \pm 80.97$ versus $117.33 \pm 74.97)$. Likewise at patients with mutant genotype AA had a lower frequency of $\mathrm{MN}$ than patients with normal GG genotype (64 versus $129.71 \pm 90.68$ ). A previous meta-analysis study of 38 published case-control studies showed that patients with CC genotype of XRCC1 have a higher one cancer risk compared to patients with mutant genotype (Norjmaa et al. 2016).

A previous study by Gong et al. (2015) stated that there is no significant correlation between the DNA repair genes of XRCC1 exon 6 and 10 genes with the risk of extrahepatic cholangiocarcinoma cancer. The integration of 
the results of this study with our research is that the study examined the correlation of polymorphism of XRCC1 exon 6 and 10 in DNA repair genes, while our study examined the correlation of DNA repair XRC1 exon 6 and 10 gene polymorphisms to the risk of DNA damage characterized by the formation of mironuclei in cancer patients. This is something different. Meanwhile, what can be taken is that the XRCC1 exon 6 and 10 genes do not significantly correlate to the risk of cancer, but there is a possibility that it correlates with the risk of DNA damage to cancer patients during radiotherapy. This is confirmed by the bystander effects theory due to radiotherapy. Marin et al. (2015) stated that radiotherapy can cause biological effects around the target cells of radiotherapy. This effect can be in the form of DNA damage, mutations, apoptosis, chromosomal instability and the emergence of ROS. It is very important to understand the bystander effects mechanism to assess radiation risk more accurate and to evaluate protocols for cancer radiotherapy.

The limitations of this study include case-control design, patient information such as smoking habits, age, and gender are not used as parameters of the study. Other limitations include ethnicity and small sample size in the case group. In addition, only actual chromosome damage (in the form of micronucleated cells) was measured in our study, so the endpoints of other chromosome damage, such as chromosome rearrangement as indicated by nucleoplasmic bridges and gene amplification as indicated by nuclear shoots, were not evaluated. The influence of lifestyle, food nutrition, and genetic variation in DNA damage response also needs to be investigated in further study.

This study exhibited a strong association of the Arg 194Trp and Arg399Gln with the extent of DNA damage and its effects on the cancer patients. These genotypes could potentially be used as a molecular biomarker to predict the risk in patients with various cancers. This approach offers the opportunity to complete cancer prevention programs for cancer patients, still based mainly on physical dosimetry. The results of this study can also be used as a recommendation for stakeholders that DNA damage can occur in patients who are taking radiotherapy. In the further studies, it is necessary to examine the DNA repair genes expression in populations linked with confounding factors, such as gender, age, lifestyles, environments that affect the micronuclei frequency as a biomarker of DNA damage.

\section{ACKNOWLEDGEMENTS}

This work was fully supported by Center for Technology of Radiation Metrology and Safety, National Nuclear Energy Agency of Indonesia. We are also grateful to our co-workers in Molecular Biology Laboratory, PTKMR, BATAN, Jakarta; Department of Radiotherapy, dr. Soetomo General Academic Hospital, Surabaya, and Department of Radiology, dr. Sardjito General Hospital, Yogyakarta for technical support.

\section{REFERENCES}

Andreassi MG, Foffa I, Manfredi S, Botto N, Cioppa A, Picano E. 2009. Genetic polymorphisms in XRCC1, OGG1, APE1 and XRCC3 DNA repair genes, ionizing radiation exposure and chromosomal DNA damage in interventional cardiologists. Mutat Res 666 (1-2): 57-63.

Caldecott KW. 2008. Single-strand break repair and genetic disease. Nat Rev Genet 9: 619-631.

Campalans A, Moritz E, Kortulewski T, Biard D, Epe B, Radicella JP. 2015. Interaction with OGG1 is required for efficient recruitment of $X R C C 1$ to base excision repair and maintenance of genetic stability after exposure to oxidative stress. Mol Cell Biol 35 (9): 1648-58.

Chang P, Li Y, Li D. 2010. Micronuclei levels in peripheral blood lymphocytes as a potential biomarker for pancreatic cancer risk. Carcinogenesis 32 (2): 210-5.

Fenech M, Holland N, Chang WP, Zeiger E, Bonassi S. 1999. The human micronucleus project: an international collaborative study on the use of the micronucleus technique for measuring DNA damage in humans. Mutat Res 428 (1-2): 271-283.

Fenech M. 2007. Cytokinesis-block micronucleus cytome assay. Nat Prot 2 (5): 1084-1104.

Gong Y, Qi M, Chen J, Fang R, Mai C, Chen T, Tang H, Tang Y. 2015. XRCC1 Arg194Trp and Arg399Gln polymorphisms and risk of extrahepatic cholangiocarcinoma: a hospital-based case-control study in China. Int J Clin Exp Med 8 (10): 19339-19345.

Greer JB, Whitcomb DC. 2009. Inflammation and pancreatic cancer: an evidence-based review. Curr Opin Pharmacol 9 (4): 411-418.

Jadhav K, Gupta N, Ahmed MB. 2011. Micronuclei: An essential biomarker in oral exfoliated cells for grading of oral squamous cell carcinoma. J Cytol 28 (1): 7-12.

Jain A, Yadav S, Beig M, Purohit S, Sharma NK. 2017. Base excision repair manipulation in breast carcinoma: A prospective avenue to potentiate genome insulting approach. Oncomedicine 2: 42-51.

Jdey W, Thierry S, Popova T, Stern MH, Dutreix M, 2017. Micronuclei frequency in tumors is a predictive biomarker for genetic instability and sensitivity to the DNA repair inhibitor AsiDNA. Cancer Res 77 (16): 4207-4216.

Jelonek K, Gdowicz-Klosok A, Pietrowska M, et al., 2010. Association between single-nucleotide polymorphisms of selected genes involved in the response to DNA damage and risk of colon, head and neck, and breast cancers in a Polish population. J Appl Genet 51 (3): 3433-52.

Khanna A. 2015. DNA damage in cancer therapeutics: a boon or a curse? Cancer Res 5 (11): 2133-2138.

Lusiyanti Y, Alatas Z, Syaifudin M, Purnami S. 2016. Establishment of a dose-response curve for $\mathrm{X}$-ray-induced micronuclei in human lymphocytes. Genome Integr 7 (49): 1-4.

Mandal RK, Kapoor R, Mittal RD. 2010. Polymorphic variants of DNA repair gene $X R C C 3$ and $X R C C 7$ and risk of prostate cancer: a study from North Indian population. DNA Cell Biol 29 (11): 669-674.

Marín A, Martín M, Linan O, Alvarenga F, Lopez M, Fernandez L, Buchser D, Cerezo L. 2015. Bystander effects and radiotherapy. Rep Pract Oncol Radiother 20 (1): 12-21.

Meng Q, Wang S, Tang W, Wu S, Gao N, Zhang C, Cao X, Li X, Zhang Z, Aschner M, Jin H, Huang Y, Chen R. 2017. XRCC1 mediated the development of cervical cancer through a novel Sp1/Krox-20 switch. Oncotarget 8 (49): 86217-8626.

Moullan N, Cox DG, Angele S, Romestaing P, Gerard JP, Hall J. 2003. Polymorphisms in the DNA repair gene XRCC1, breast cancer risk, and response to radiotherapy. Cancer Epidemiol Biomarkers Prev 12: 1168-74.

Norjmaa B, Tulgaa K, Saitoh T. 2016. Base excision repair pathway and polymorphisms of XRCC1 gene. J Mol Pathol Epidemiol 1 (1): 1-4

Ochiai H. 2015. Single-base-pair genome editing in human cells by using site-specific endonucleases. Intl J Mol Sci 16 (9): 21128-2137.

O'Connor MJ. 2015. Targeting the DNA Damage Response in Cancer. Mol Cell 60 (4): 547-560.

Rothfuss A, Schutz P, Bochum S, Volm T, Eberhardt E, Kreienberg R, et al., 2000. Induced micronucleus frequencies in peripheral lymphocytes as a screening test for carriers of a BRCA1 mutation in breast cancer families. Cancer Res 60 (2): 390-394.

Rybicki BA, Conti DV, Moreira A, Cicek M, Casey G, Witte JS. 2004. DNA repair gene $X R C C 1$ and $X P D$ polymorphisms and risk of prostate cancer. Cancer Epidemiol Biomarkers Prev 13 (1): 23-29. 
Ryu RA, Tae K, Min HJ, et al. 2011. XRCC1 Polymorphisms and risk of papillary thyroid carcinoma in a Korean Sample. J Korean Med Sci 26 (8): 991-995.

Surniyantoro HNE, Lusiyanti Y, Rahardjo T, Nurhayati S, Tetriana D. 2018c. Association between XRCC1 exon 10 (Arg399Gln) gene polymorphism and micronucleus as a predictor of DNA damage among radiation workers. Biodiversitas 19 (5): 1676-1682.

Surniyantoro HNE, Lusiyanti Y, Rahardjo T, Tetriana D, Nurhayati S, Date H. 2018b. Polymorphism of XRCC1 Gene Exon 6 (Arg194Trp) in Relation to Micronucleus Frequencies in Hospital Radiation Workers. Atom Indonesia 44 (2): 105-111.

Surniyantoro HNE, Sadewa AH, Hastuti P, 2018a. Uncoupling protein 2 (UCP2) as genetic risk factor for obesity in Indonesia is different in gender stratification. Kobe J Med Sci 64 (2): 64-72.
Wallace SS, Murphy DL, Sweasy JB. 2012. Base excision repair and cancer. Cancer Lett 327 (1-2): 73-89.

Wells OS, El-Khamisy SF. 2015. Autosomal recessive ataxias due to defects in DNA repair. Mov Disorders 1033-1041.

Widel M, Jedrus S, Owczarek S, Konopacka M, Lubecka B, Kołosza Z. 1999. The increment of micronucleus frequency in cervical carcinoma during irradiation in vivo and its prognostic value for tumour radiocurability. Br J Cancer 80 (10): 1599-1607.

Yuan Z, Li J, Hu R, Jiao Y, Han Y, Weng Q. 2015. Predictive assessment in pharmacogenetics of XRCC1 gene on clinical outcomes of advanced lung cancer patients treated with platinum-based chemotherapy. Sci Rep 5 (16482): 1-21. 